\title{
Spatial trends in leaf size of Amazonian rainforest trees
}

\author{
A. C. M. Malhado ${ }^{1, *}$, Y. Malhi ${ }^{1, * *}$, R. J. Whittaker ${ }^{1, * *}$, R. J. Ladle ${ }^{1, * *}$, H. ter Steege ${ }^{2, * *, * * *}$, O. L. Phillips ${ }^{3, * *, * * *}$, \\ N. Butt ${ }^{1, * *}$, L. E. O. C. Aragão ${ }^{1, * * *}$, C. A. Quesada ${ }^{3, * * *}$, A. Araujo-Murakami ${ }^{4, * * *}$, L. Arroyo ${ }^{4, * *}$, J. Peacock $^{3, * * *}$, \\ G. Lopez-Gonzalez ${ }^{3, * * *}$, T. R. Baker ${ }^{3, * * *}$, L. O. Anderson ${ }^{1, * *}$, S. Almeida ${ }^{5, * * *}$, N. Higuchi ${ }^{6, * * *}$, T. J. Killeen ${ }^{7, * *}$,

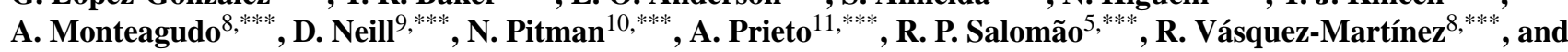 \\ W. F. Laurance ${ }^{6, * * *}$ \\ ${ }^{1}$ School of Geography and the Environment, Oxford University, UK \\ ${ }^{2}$ Dept. of Plant Ecology and Biodiversity, Utrecht University, The Netherlands \\ ${ }^{3}$ Earth and Biosphere Institute, School of Geography, University of Leeds, UK \\ ${ }^{4}$ Museo Noel Kempff Mercado, Santa Cruz, Bolivia \\ ${ }^{5}$ Museu Paraense Emilio Goeldi, Belém, Brazil \\ ${ }^{6}$ Instituto National de Pesquisas Amazônicas, Manaus, Brazil \\ ${ }^{7}$ Center for Applied Biodiversity Science, Conservation International, Washington, DC, USA \\ ${ }^{8}$ Herbario Vargas, Universidad Nacional San Antonio Abad del Cusco, Cusco, Perú \\ ${ }^{9}$ Herbario Nacional del Ecuador, Quito, Ecuador \\ ${ }^{10}$ Center for Tropical Conservation, Duke University, Durham, USA \\ ${ }^{11}$ Instituto de Investigación de Recursos Biológicos Alexander von Humboldt, Bogotá DC, Colombia \\ * Conceived the study, collected leaf data, undertook the analysis, wrote manuscript. \\ ** Developed the idea, reviewed and improved manuscript. \\ **** Provided data.
}

Received: 17 December 2008 - Published in Biogeosciences Discuss.: 23 February 2009

Revised: 17 June 2009 - Accepted: 3 August 2009 - Published: 10 August 2009

\begin{abstract}
Leaf size influences many aspects of tree function such as rates of transpiration and photosynthesis and, consequently, often varies in a predictable way in response to environmental gradients. The recent development of panAmazonian databases based on permanent botanical plots has now made it possible to assess trends in leaf size across environmental gradients in Amazonia. Previous plot-based studies have shown that the community structure of Amazonian trees breaks down into at least two major ecological gradients corresponding with variations in soil fertility (decreasing from southwest to northeast) and length of the dry season (increasing from northwest to south and east). Here we describe the geographic distribution of leaf size categories based on 121 plots distributed across eight South American countries. We find that the Amazon forest is predominantly populated by tree species and individuals in the mesophyll size class $\left(20.25-182.25 \mathrm{~cm}^{2}\right)$. The geographic distribution of species and individuals with large leaves $\left(>20.25 \mathrm{~cm}^{2}\right)$ is complex but is generally characterized by a higher proportion
\end{abstract}

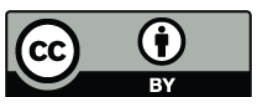

Correspondence to: A. C. M. Malhado (anaclaudiamalhado@gmail.com) of such trees in the northwest of the region. Spatially corrected regressions reveal weak correlations between the proportion of large-leaved species and metrics of water availability. We also find a significant negative relationship between leaf size and wood density.

\section{Introduction}

Leaf size is one of the most plastic traits of a tree and it is not uncommon to see great variability within genera, species, individuals within a species, and even between the same individual at different stages of development (e.g. sapling, canopy tree) or on different parts of the same tree (e.g. sun versus shade leaves). Despite this very large variation it is often possible to detect significant associations between a range of environmental variables and leaf size. For example, Givnish (1987) reviewed comparative studies of leaf form and concluded that effective leaf size - the width of a leaf or its lobes or leaflets - increases along gradients of increasing rainfall, humidity and/or soil fertility, and decreases with increasing irradiance. Leaf size also tends to decrease with increasing elevation on mountains in regions receiving high

Published by Copernicus Publications on behalf of the European Geosciences Union. 
rainfall at low elevation, and to increase and then decrease with elevation in more arid regions. Givnish (1987) also observed that older plants often possess smaller leaves than younger ones of the same species.

The existence of broad-scale (macrogeographic) environment-leaf size correlations probably reflect the evolutionary response of this trait to its environment (Givnish, 1987; Westoby et al., 2002). The size of leaves on a tree can therefore be productively considered as a "solution" to the complex environmental "problems" of, most notably, light capture for photosynthesis (Falster and Westoby, 2003), economics of gas and water vapour exchange (Givnish and Vermeij, 1976; Givnish, 1984), avoidance of heat stress from intense sunlight, mechanical stability (Westoby et al., 2002), and defence against herbivores (Moles and Westoby, 2000). Certainly the size of a leaf is by no means ecologically trivial since, as Givnish (1987) points out, leaf size variation will have a direct effect on whole-plant growth rate, mainly through size-related changes in the conductance of the boundary layer, which affects heat exchange, uptake of carbon dioxide and loss of water vapour.

Leaf size theory predicts that the costs and benefits of a "large leaf" or a "small leaf" strategy should vary in a predictable way with environmental parameters such as humidity, water availability, and soil fertility (Parkhurst and Loucks, 1972; Givnish and Vermeij, 1976; Givnish, 1978, 1979, 1984; Westoby et al., 2002). Larger leaves have a thicker boundary layer of slow-moving, non-turbulent air and slower convective heat loss and therefore tend to be hotter than ambient air temperature when exposed to net incoming radiation. This can be disadvantageous, especially in areas where water is limiting, because it may lead to higher rates of respiration and decreased rates of photosynthesis (Lloyd and Farquhar, 2008) through the following mechanism: higher leaf temperatures cause a higher water vapour deficit that, in turn, leads to increased transpiration/water loss. The plant adaptively responds to this by closing stomata, which has the net effect of reducing $\mathrm{CO}_{2}$ uptake and reducing the rate of photosynthesis. Reduced water availability might therefore be expected to favour smaller leaves (Givnish, 1987). With respect to soil fertility, trees growing in oligotrophic (low nutrient) soils may, all other things being equal, be limited in their rate of construction of photosynthetic enzymes and therefore benefit less from temperature-related increases in photosynthetic metabolism - once again favouring the evolution and development of smaller leaves (Givnish, 1984, 1987). However, predictions such as these need to be treated with caution and may not hold true under all circumstances since leaves may have other adaptations (e.g. sclerophylly) that strongly influence the optimal leaf size strategy under any particular set of environmental conditions.

The complex nature of the relationship between environment and leaf size is also reflected by the considerable variation in leaf size that can be observed within areas with similar macroclimatic conditions (Cornelissen, 1999). In other words, many different leaf size strategies frequently co-exist in physically similar environments. It is likely that withinsite (or within plot) variation in leaf size arises because the ecological opportunities for each species are also strongly dependent on the other species present in the community (Westoby et al., 2002). Thus, the ability of a species to establish successfully in a habitat may be dependent upon which other species are present and may be influenced by other traits apart from leaf form and size. These complex trade-offs and the multiple selective pressures on leaf size have generated considerable diversity in this trait, even between ecologically similar species (Ackerly, 1996).

Care should also be taken not to interpret everything purely in terms of optimisation of a single trait (leaf size) since developmental and physiological constraints and tradeoffs (cf. Dawkins, 1982) may also play a role in determining leaf size. This is clearly illustrated by the associations between leaf size and canopy architecture and branching morphology (Midgley and Bond, 1989; Ackerly and Donoghue, 1998). Furthermore, these latter traits may, in turn, influence leaf size evolution independent of ecophysiological function (Ackerly and Reich, 1999). An example of the importance of such trade-offs could be the commonly observed negative relationship between wood density and leaf size (reviewed in Wright et al., 2007). The explanation for this relationship is still uncertain but may relate to the higher hydraulic conductivity of trees with low-density wood that allows them to deploy a larger total leaf area per stem (Wright et al., 2007). Alternatively, this relationship is perhaps related to the "pioneer-climax" tree gradient or may be due to co-varying factors that do not directly interact and are therefore difficult to identify. However, the fact that there is still considerable variation in leaf size between species with similar wood densities suggests that this is by no means the whole story.

Despite the fact that ecologists have had a long-standing interest in explaining variations in leaf size between, and within, species and habitats it is still a subject that appears far from resolution. For instance, Westoby et al. (2002) consider the leaf size-twig size spectrum of ecological variation as being fundamental to our understanding of the texture and function of forest canopies, but acknowledge that the costs and benefits of large versus small leaf and twig size are still poorly understood. Ackerly and Reich (1999, p. 1279) also feel obliged to admit that, "variation (in leaf size) among species within habitats is still poorly explained".

Givnish (1987), in his agenda-setting review of comparative studies in leaf form, suggests two methodological approaches that may lead towards a better understanding of leaf size. Firstly, in-depth physiological studies may be able to tease apart the various constraints and trade-offs that affect leaf size (e.g. Parkhurst and Loucks' (1972) general eco-physiological model of leaf size). Secondly, broader comparative studies are required, since the more intensive physiologically-based approaches will necessarily be subject 
to biases stemming from a range of genetic influences such as linkage, epistasis and pleiotropy that are peculiar to the study population, in addition to any influence of natural selection.

In this paper we adopt the broader comparative approach advocated by Givnish (1987). With the recent creation of very large databases of Amazonian trees based on permanent plots scattered throughout the Amazon region it has now become possible to conduct a comprehensive study of broad scale patterns of leaf size variation within the largest block of rainforest in the world. Here, we use the RAINFOR database of 121 permanent plots to: 1) describe the spatial distribution of leaf size categories across the Amazon Basin and Guyana Shield, and; 2) investigate the environmental factors driving regional scale patterns in leaf size. We do this to gain further insights into the ecological significance of leaf size and improve our understanding of the functioning of the Amazonian rainforest.

Specifically, we seek answers to the following questions:

- Which leaf size categories dominate the canopy of the Amazon rainforest?

- Are there spatial patterns in leaf size distribution in Amazonia?

- Are the frequencies of different leaf size categories associated with environmental variables that reflect their adaptive function (e.g. rainfall, soil fertility, and length of dry season)?

- Are leaf size categories associated with the growth strategy of trees?

- Are leaf size and wood density negatively correlated?

We will test the following key hypotheses about leaf size in Amazonia: a) small leaves are an adaptation to relatively drier conditions and will show a macrogeographic pattern that reflects this; b) small leaves are favoured on oligotrophic soils; and c) there is a negative relationship between leaf size and wood density.

\section{Material and methods}

\subsection{Database construction}

Our main source of data and research tool for exploring spatial variation in leaf size categories across the Amazon basin was the RAINFOR database (Peacock et al., 2007 ${ }^{1}$ ) and 26 plots from the Guyanas and Suriname compiled by the ATDN network (ter Steege et al., 2003). The combined database uses information from 141 permanent plots distributed across eight South American countries. However, not all data were available for all plots, so plots lacking relevant environmental data were removed from certain analyses. 20 plots were also excluded from the study because they had $>30 \%$ of species that were either unidentified at species level ( 475 species from entire database) or for which herbarium/flora data were not available (61 species). As a consequence, the number of plots included in the analyses varied from 51 to 121 . The database at the time of extraction for this study (August 2006) contained 111123 individual trees $(\geq 100 \mathrm{~mm}$ DBH) from 3324 species.

The plots used in this study span local and regional environmental gradients that naturally occur in Amazonia, including mature forests that are seasonally flooded, waterlogged and non-flooded lowland terra firme forests $(88 \%$ of plots) on both clay-rich and white-sand substrates. All sites consisted of an apparently mature old-growth forest with natural gap-phase dynamics and a canopy dominated by non-pioneer species. None of the plots is believed to have experienced any recent human-caused disturbance. The individual plots range in size from 0.25 to 9 ha $(1.17$ ha $\pm 1.04=$ mean \pm SD $)$ and in total encompass 141.5 ha of forest. The density of stems per plot (including undetermined stems) ranged from 265 to 1307 perha $(672 \pm 167$ per ha $=$ mean \pm SD $)$.

To this existing database, information was added on leaf size for each species (2788) using digital images from floras and herbaria (Table 1). A digital image, representing an average leaf for a particular species, was located using a number of online herbaria. Leaf-size was determined from the herbarium or flora specimen using the geometric leaf-size classification of Raunkiaer (1934) as modified by Webb (1959). Raunkiaer (1934) defined six leaf-size classes: leptophyll (leaves up to $0.25 \mathrm{~cm}^{2}$ in area), nanophyll $(0.25-$ $\left.2.25 \mathrm{~cm}^{2}\right)$, microphyll $\left(2.25-20.25 \mathrm{~cm}^{2}\right)$, mesophyll (20.25$\left.182.25 \mathrm{~cm}^{2}\right)$, macrophyll $\left(182.25-1640.25 \mathrm{~cm}^{2}\right)$, and megaphyll ( $>1640.25 \mathrm{~cm}^{2}$ ). Webb (1959) divided the mesophyll size class into two further size classes (see Table 2): notophyll $\left(20.25-45.0 \mathrm{~cm}^{2}\right)$ and mesophyll $\left(45.0-182.25 \mathrm{~cm}^{2}\right)$.

\subsection{Leaf size metrics}

The spatial patterns of variation in leaf size were assessed through the use of several simple metrics, which then acted as dependent variables within OLS (Ordinary Least Squares) regressions. Following Dolph and Dilcher (1980), our main metrics for describing the geographic distribution of leaf sizes are the proportion of species or individuals that possess large leaves (Category 5, mesophyll; Category 6, macrophyll; and Category 7, megaphyll). Where appropriate for analysis or illustration we also collapse Categories 6 and 7 into a combined "very-large" leaves category (Table 2). Furthermore, palm trees were placed in a separate palm-leaf category and were only used to report abundance.

\footnotetext{
${ }^{1}$ http://www.rainfor.org
} 
Table 1. List of floras and herbaria used as information sources and number of species retrieved from each source.

\begin{tabular}{llr}
\hline & Source & Total species \\
\hline 1. & Neotropical Herbarium Specimens - The Field Museum & 1918 \\
2. & New York Botanical Garden & 160 \\
3. & The Nationaal Herbarium Nederland (NHN) & 159 \\
4. & Flórula de las Reservas Biológicas de Iquitos, Perú. Vásquez-Martínez (1997) & 154 \\
5. & Mobot - Missouri Botanical Gardens Herbarium & 140 \\
6. & Centre IRD de Cayenne, French Guiana & 99 \\
7. & Instituto Nacional de Pesquisas da Amazônia Herbarium, INPA, Brazil & 55 \\
8. & Botanic Garden and Botanical Museum, Berlin, Germany & 18 \\
9. & Cain et al. (1954) & 18 \\
10. & Museu Paraense Emilio Goeldi Herbarium, Brazil & 16 \\
11. & Oxford University - Plant Science Herbarium, UK & 13 \\
12. & The Herbarium of the University of Aarhus, AAU, Denmark & 9 \\
13. & HerbW - Virtual Herbaria Austria & 4 \\
14. & http://images.nbii.gov/ & 2 \\
15. & Others & 23 \\
\hline
\end{tabular}

Table 2. Derivation and correspondence of leaf size categories used in study. Collapsed categories are used as dependent variables in analyses.

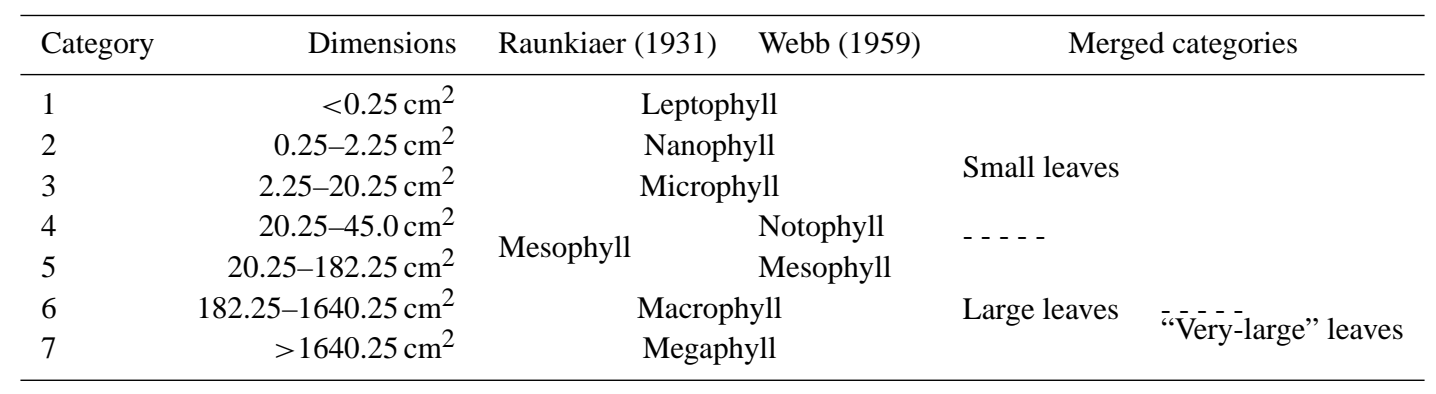

\subsection{Geographic trends in leaf size}

Previous studies using the RAINFOR database have suggested that forests in Western Amazonia have higher wood productivity (Malhi et al., 2004), higher turnover (Phillips et al., 2004), and lower wood density and biomass (Baker et al., 2004) than forests growing on infertile soils further east. Here, to aid direct comparisons with these studies (including a variety of leaf traits - e.g. Malhado et al., 2009), we follow the practice of splitting the Amazon into four main regions: Region 1, North Amazonia, containing plots from Guyana, Suriname and Venezuela; Region 2, Northwest Amazonia, containing plots from Ecuador, Colombia, and North Peru; Region 3, Central and East Amazonia, all Brazilian plots (states of Amazonas and Pará only); Region 4, Southwest Amazonia, containing plots from Bolivia and South Peru.

The regional distribution of leaf size might be affected by the distribution of the largest family, the Fabaceae, so analyses were repeated both with the Fabaceae removed dataset and within the Fabaceae dataset.
To better detect and visualize regional patterns in leaf size categories, and accounting for tree diameters, we also quantified the relative contribution (proportion) of each leaf size (Categories 1 to 6 ) across eight tree trunk diameter $(\mathrm{DBH})$ classes $(100-190 \mathrm{~mm},>190-280 \mathrm{~mm},>280$ $370 \mathrm{~mm},>370-480 \mathrm{~mm},>480-550 \mathrm{~mm},>550-640 \mathrm{~mm}$, $>640-730 \mathrm{~mm},>730 \mathrm{~mm}$ ) for each region. The relative abundance was quantified through a two-stage process: first, the proportion of trees within each DBH category within a region was calculated; second, the relative proportion of each size class across the four regions was calculated (proportion

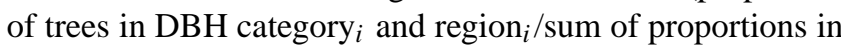
category for all regions).

\subsection{Life history metrics}

In this paper, we define the growth strategy of each species through a simple index (henceforth referred to as the pioneer index) based on expert judgment. The pioneer index was used to rank genera according to the extent to which they are 
perceived to be pioneers (plants that are specialists in forest gaps and other disturbed areas). This index reflects the degree of consensus among botanists familiar with the taxa, in this case Oliver Phillips, Rodolfo Vásquez-Martínez, and Abel Monteagudo, and was cross-referenced with herbarium material collector's labels. To calculate the index each taxon was judged independently by each botanist and given a value between zero ("non-pioneer") and one ("pioneer"). The pioneer index was then calculated as the average score for each species. Wood density for each species was calculated using information available in the RAINFOR database (Baker and Lopez-Gonzalez, 2006) and derived from published sources (Baker et al., 2004; Peacock et al., 2007).

\subsection{Environmental variables}

The choices of independent (predictor) variables for our spatially controlled regression models were based on both observation and theory. Since one of the main hypotheses is that small leaves in tropical forests are an adaptation to relatively drier conditions (Givnish, 1984, 1987), we used a series of metrics of precipitation retrieved from the monthly TRMM (Tropical Rainfall Measuring Mission - TRMM 3B43-V6, $0.25^{\circ}$ spatial resolution). This product combines multiple data sources including satellite information on rainfall with ground precipitation gauge adjustment (Huffman and Bolvin, 2007). These data have recently been shown to accurately represent the rainfall patterns over the Amazonian region (Aragão et al., 2007). For each month we calculate the average mean from 1998 to 2005 . The monthly mean surfaces (one for each month of the year, combining twelve geo-referenced surfaces) were then used to estimate for each pixel: (1) the annual rainfall $\left(\mathrm{mm}\right.$ year $\left.^{-1}\right)$, based on the sum of the monthly values; (2) the standard deviation (SD) of rainfall within the year, as a measure of seasonality; (3) the maximum climatological water deficit (MWD; mm), calculated by assuming that the evapotranspiration rate is approximately $100 \mathrm{~mm} \mathrm{month}^{-1}$ in tropical forests and a cumulative deficit is thus incurred if the rainfall is less than this value (Aragão et al., 2007); and (4) the length of the dry season, as the number of months with rainfall $<100 \mathrm{~mm}$ (Fig. 1). Although crude, the MWD is thought to be a useful indicator of meteorologically-induced water stress without taking into account local soil conditions and plant adaptations, and its annual variation has been shown to strongly affect tree mortality (Phillips et al., 2009).

Small leaves may also be favoured on oligotrophic soils even under wet conditions (Givnish, 1987) and we therefore used data on soil fertility (sum of bases), where available (51 plots, Quesada et al., 2009). Soil sampling for the sites was carried out in accordance with a standard protocol developed for the RAINFOR project ${ }^{2}$. Soil pits were situated at representative locations for the dominant soil and

\footnotetext{
${ }^{2}$ http://www.geog.leeds.ac.uk/projects/rainfor/projdocs.html
}

topographic positions, usually located a few metres outside the permanent sample plots in order to reduce potential disturbances. All soil samples were analysed (Quesada et al., 2009) and exchangeable $\mathrm{Ca}, \mathrm{Mg}, \mathrm{K}, \mathrm{Na}$ and $\mathrm{Al}$ were determined by the silver thiourea method (Pleysier and Juo, 1980) as described in detail in ISRI (1995). The sum of bases $(\mathrm{SB})$ was calculated as: $[\mathrm{SB}]=[\mathrm{Ca}]+[\mathrm{Mg}]+[\mathrm{K}]+[\mathrm{Na}]$ (Units: $\mathrm{mmol} \mathrm{kg}^{-1}$ ). Soil analyses ranged from regional to global scales and used individual leaf size categories (leaf Categories 1, 2, 3, 4, 5, 6) and clustered categories (small, large, "very-large") for partial datasets (all trees, Fabaceae removed, only Fabaceae).

\subsection{Statistical analysis}

Leaf size varied considerably within taxonomic groups in the study, suggesting that it is unnecessary to control formally for phylogeny. However, RAINFOR plots do show a degree of spatial clustering and ecological and physical variables may therefore be more similar (or dissimilar) because of spatial proximity, and it is therefore appropriate to account statistically for spatial autocorrelation (Legendre, 1993). With multiple variables it is a common strategy to perform Ordinary Least Squares (OLS) regressions of response variables (in this case metrics of leaf size) on the raw environmental factors and use Moran's I correlograms to check for the presence of spatial autocorrelation in the residuals (Rangel et al., 2006). When correlograms showed evidence of spatial autocorrelation we used a spatial filtering approach to control for the influence of spatial position on the relationship between explanatory and response variables. Furthermore, we tested for an association between the sum of bases (plot soil fertility data) and proportion of leaf size categories adjusting for the number of degrees of freedom using Dutilleul's (1993) method. All spatial analyses were performed using the software Spatial Analysis in Macroecology (SAM v2) (Rangel et al., 2006).

Trends in the distribution of the various leaf size metrics (see Materials and Methods) in relation to the four Amazonian regions (regional analyses) were assessed using a oneway analysis of variance (ANOVA). We used Kruskal Wallis test to assess relationship between leaf size categories and pioneer index and wood density. These analyses were performed using SPSS 14.0. Significance level was set at $5 \%(0.05)$ for all inferential statistics.

\section{Results}

\subsection{Abundance of leaf size categories}

Based on our analysis of herbaria specimens, among the 2788 studied species $50 \%$ fell into the mesophyll (Webb) category (Category 5), 1.2\% leptophyll, 1.3\% nanophyll, 7.6\% microphyll, $23.6 \%$ notophyll, $13.7 \%$ macrophyll, and $0.1 \%$ megaphyll (Fig. 2). The final $2 \%$ were palms, which were 


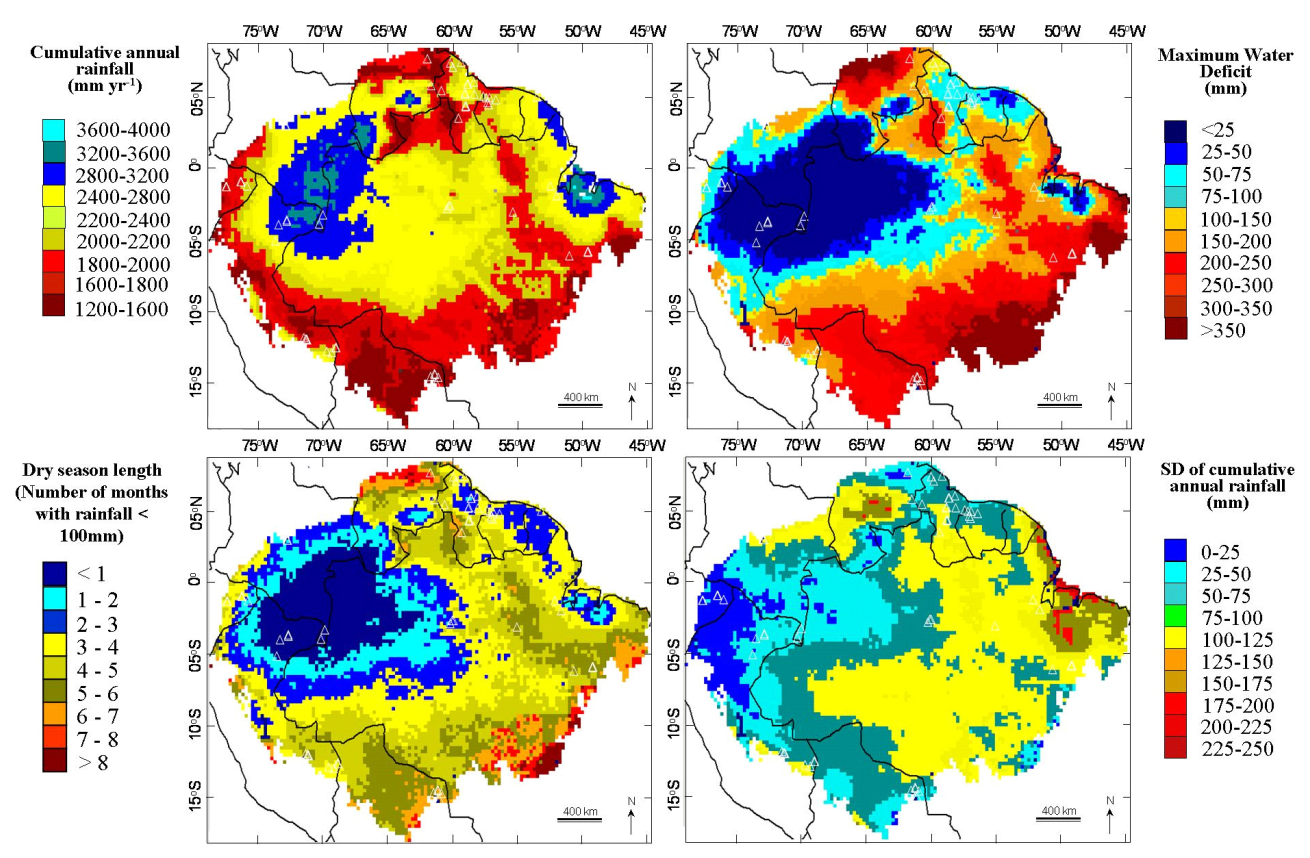

Fig. 1. The spatial distribution of four water availability variables across Amazonia: total annual rainfall, maximum water deficit (MWD), length of the dry season, and standard deviation of total annual rainfall. These data were derived from the Tropical Rainfall Measuring Mission (TRMM - from 1998 to 2005).

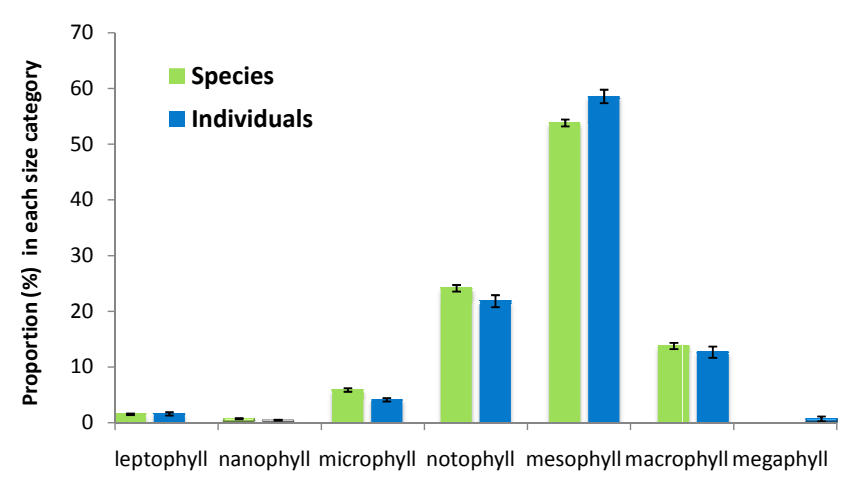

Fig. 2. Mean percentage of species and individual trees in different leaf size categories in 121 Amazonian plots. Error bars=1 standard error of the mean.

excluded from further analysis. The proportion of individual trees that fall into different leaf size categories closely mirror the observed proportion of species: 52.4\% of 84554 individual trees fell into mesophyll category, $1.3 \%$ were leptophyll, $0.6 \%$ nanophyll, $4.1 \%$ microphyll, $18.5 \%$ notophyll, $11.9 \%$ macrophyll, and $0.6 \%$ megaphyll (Fig. 2). Palms account for $10.5 \%$ of the total number of individual trees across the studied plots.

Leaf size classes are broadly distributed within and between families. This is clearly illustrated by the proportion of families that contain species in two leaf size categories $(24.7 \%)$, three leaf size categories $(29.6 \%)$ or four leaf size categories (30.9\%). Only $13.6 \%$ of the families were characterized by all their species belonging to a single leaf size category - although it is important to note that the vast majority of these families contained only 1 or 2 species. The speciesrich Fabaceae family is the group with the largest distribution of leaf size categories and is characterised by species that are represented in 6 (out of the 7) leaf classes.

The leaf size distribution of the largest families (those with $>60$ species) follows a unimodal distribution with a distinct peak in the mesophyll leaf size category (Fig. 3a). Further analyses on families where all species possess simple leaves and on families displaying at least one species with compound leaves (leaflets) also followed a unimodal distribution (Fig. 3b, c). Two families deviate from the general form: the Fabaceae and Myrtaceae, both of which are characterized by a flatter distribution (lower kurtosis) of leaf size categories.

\subsection{Spatial trends in leaf size}

There is a significant difference in the mean proportion of species with large leaves (Categories 5 to 7 ) among the four Amazonian regions $(n=121, d f=3, F=14.455, p<0.001)$, with plots from Northwest Amazonia (Region 2) possessing a greater proportion of larger-leaved species on average than plots from the other regions (Fig. 4). It is interesting to note that Region 4 appears to consist of two quantitatively distinct clusters of plots (Fig. 4), a western set and an eastern set. The northwestern cluster (nearest to Region 2) features forests with a similar proportion of large-leaved trees to those 

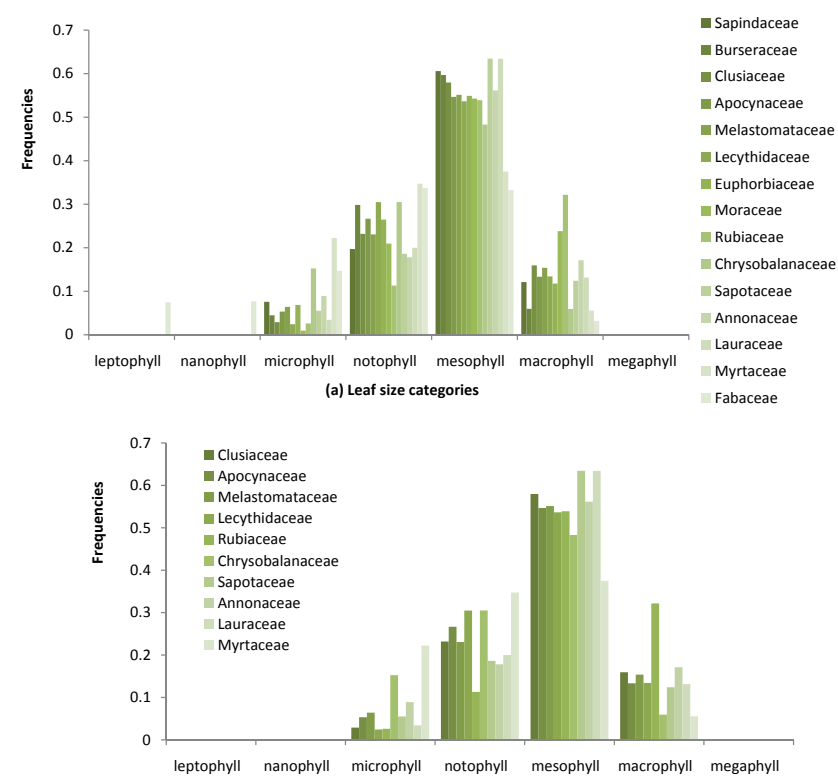

(b) Leaf size categories (simple leaf)

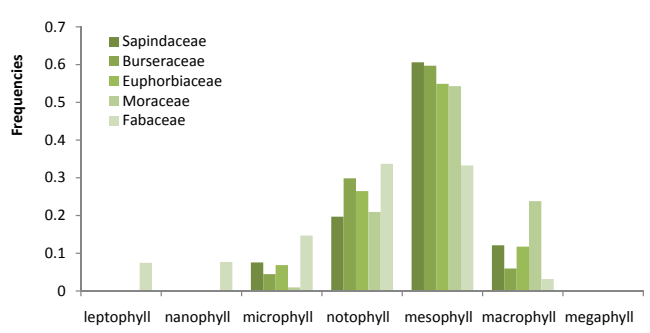

(c) Leaf size categories (compound leaf)

Fig. 3. Leaf size distributions of the largest (most species rich) families ( $>60$ species) in the RAINFOR dataset: (a) all large families; (b) excluding families that have any species with compound leaves; (c) families that have one or more species displaying compound leaves.

found in plots in Region 2. When the analysis is repeated using the two largest leaf size categories (Categories 6 and 7), a significant difference is found between the mean proportion of species with leaves in these classes between all 4 regions. In this case, Northwest Amazonia (Region 2) once again has the greatest proportion of species with the largest leaves, followed by Southwest Amazonia (Region 4), Central and Eastern Amazonia (Region 3), and finally, North Amazonia (Region 1).

Very similar geographical patterns are observed when we consider relative abundance of individual trees with large leaves (Categories 5 to 7), or "very-large" leaves (Categories 6 and 7).

There is still a significant difference among the four regions in terms of the mean proportion of trees with large leaves (and "very-large" leaves) when we control for the possible influence of the numerically abundant Fabaceae family. Specifically, when all the Fabaceae trees are removed from the analysis there was a significant difference observed for

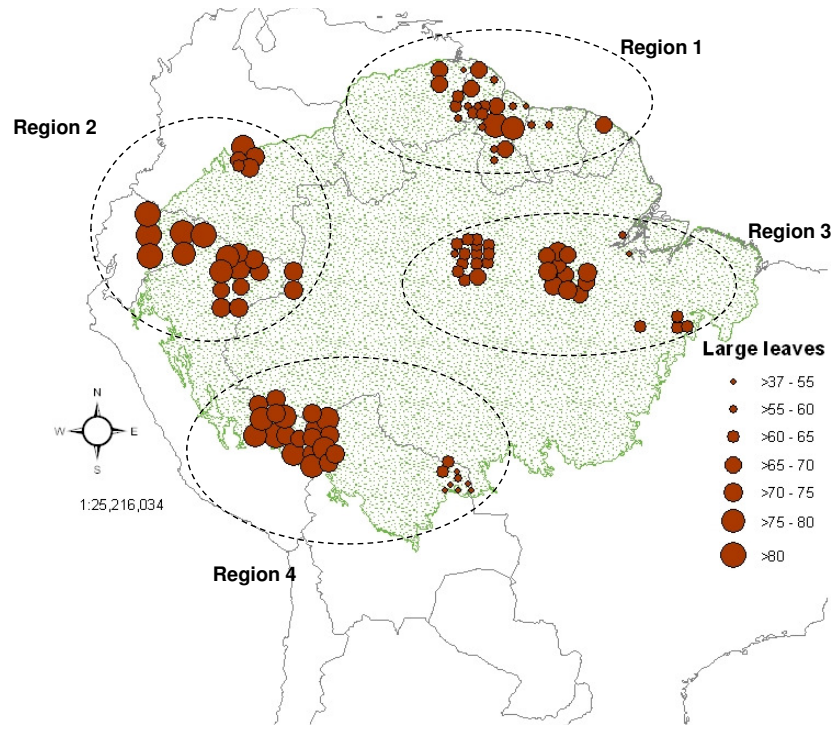

Fig. 4. Map of the incidence of species with large leaf size category (Categories 5 to 7) in each plot organized by proportion categories and regions (Region 1, North Amazonia; Region 2, Northwest Amazonia; Region 3, Central and East Amazonia; Region 4, Southwest Amazonia). For the purposes of clear visualisation the positions of some plots within clusters have been adjusted, and may not correspond to exact geographic location.

individual trees with large leaves among the regions $(n=118$, $d f=3, F=13.068, p<0.001)$. Tukey's post-hoc test reveals two distinct clusters: 1) North and Southwest Amazonia (Regions 1 and 4) that display a lower mean proportion of trees with large leaves, and 2) Northwest Amazonia and Central-Eastern Amazonia (Regions 2 and 3) that display a higher mean proportion of trees with large leaves. An identical geographical pattern and level of significance was observed when the proportion of trees with "very-large" leaves (classes 6 and 7) was used as the dependent variable $(n=118$, $d f=3, F=7.464, p<0.001)$.

When the analysis was repeated within the Fabaceae only we found a weakly significant difference among the regions in the mean proportion of trees with large leaves $(n=118$, $d f=3, F=2.715, p=0.048)$. In this case Northwest Amazonia (Region 2) still contains the largest mean proportion of Fabaceae trees with large leaves although Tukey's post hoc test revealed that none of the means (for regions) are statistically different from each other. However, when the same test is performed using the mean proportion of Fabaceae trees with "very-large" leaves a strongly significant result is gained $(n=118, d f=3, F=4.639, p=0.004)$, once again following the "typical" geographic pattern outlined above: trees with "very-large" leaves being relatively less abundant in North and Southwest Amazonia and relatively more abundant in Northwest Amazonia and Central-Eastern Amazonia. 
The mean frequency of different leaf size categories shows a consistent pattern across the four Amazonian regions and is characterized by the dominance of individual trees in the mesophyll category (Fig. 5a). Region 1 (North Amazonia) has a slightly larger frequency of smaller-leaved individuals (Fig. 5a). An almost identical pattern of mesophyll dominance is repeated when the most numerically abundant and species rich family, the Fabaceae, are removed from the dataset with Region 1 conforming most closely to the "typical" pattern (Fig. 5b). When the size distribution of individuals within the Fabaceae is plotted each region appears to have its own singular distribution (Fig. 5c).

We also looked at the relative proportion of individual trees in each leaf size category in relation to regions and DBH classes (Fig. 6). The distribution of trees in leaf size Categories 1 and 2 is in concordance with the distribution of Fabaceae across the regions and DBH size classes. Relative proportions of trees in leaf size Categories 3 and 4 are relatively even among our regions, although it is possible to detect a slight increase in relative proportion for Region 4 for trees in the higher DBH ranks (Fig. 6). The relative proportions of trees in leaf size classes 5 and 6 are very consistent in smaller DBH categories but show a trend of increasing regional separation in the higher DBH categories (Fig. 6). Regional analysis of small (classes 1 to 4 combined) and large leaves (classes 5 to 7 combined) reveals a singular pattern in Region 4 (Southwest Amazonia), which is distinguished by a higher proportion of large DBH trees that possess either smaller leaves or larger leaves (Fig. 7). Region 1 shows a trend of a relatively lower proportion of large leaved trees in larger DBH categories (Fig. 7).

\subsection{Leaf size and tree characteristics}

Species with small leaves show significantly lower "pioneer" scores than species with large leaves $\left(x^{2}=10.215, d f=1\right.$, $p=0.001$ ). A more detailed analysis using leaf categories one to six also shows a significant difference in identified growth strategy among the classes $\left(x^{2}=18.332, d f=5, p=0.003\right)$. Further analysis reveals that the significance is being primarily driven by the growth strategy of species with large leaves (Category 6$)^{3}$, which are characterized by almost $40 \%$ higher mean scores than species with smaller leaf sizes (Categories 3, 4 and 5).

Species with large leaves (Categories 5 to 7) have lower wood density (approximately 10\% less) when compared with species with small leaves (Categories 1 to 4$)\left(x^{2}=23.885\right.$, $d f=1, p<0.001$; mean wood density large leaves: 0.62 ; small leaves: 0.68 ). Individual trees with small leaves tend to have larger diameters (DBH), while larger leaves present smaller diameters although, interestingly, it is also possible to find individual trees with large DBH possessing large leaves.

\footnotetext{
${ }^{3}$ Species in the largest leaf size category (7) were not significant in this test, possibly because they account for a very small propor-
}
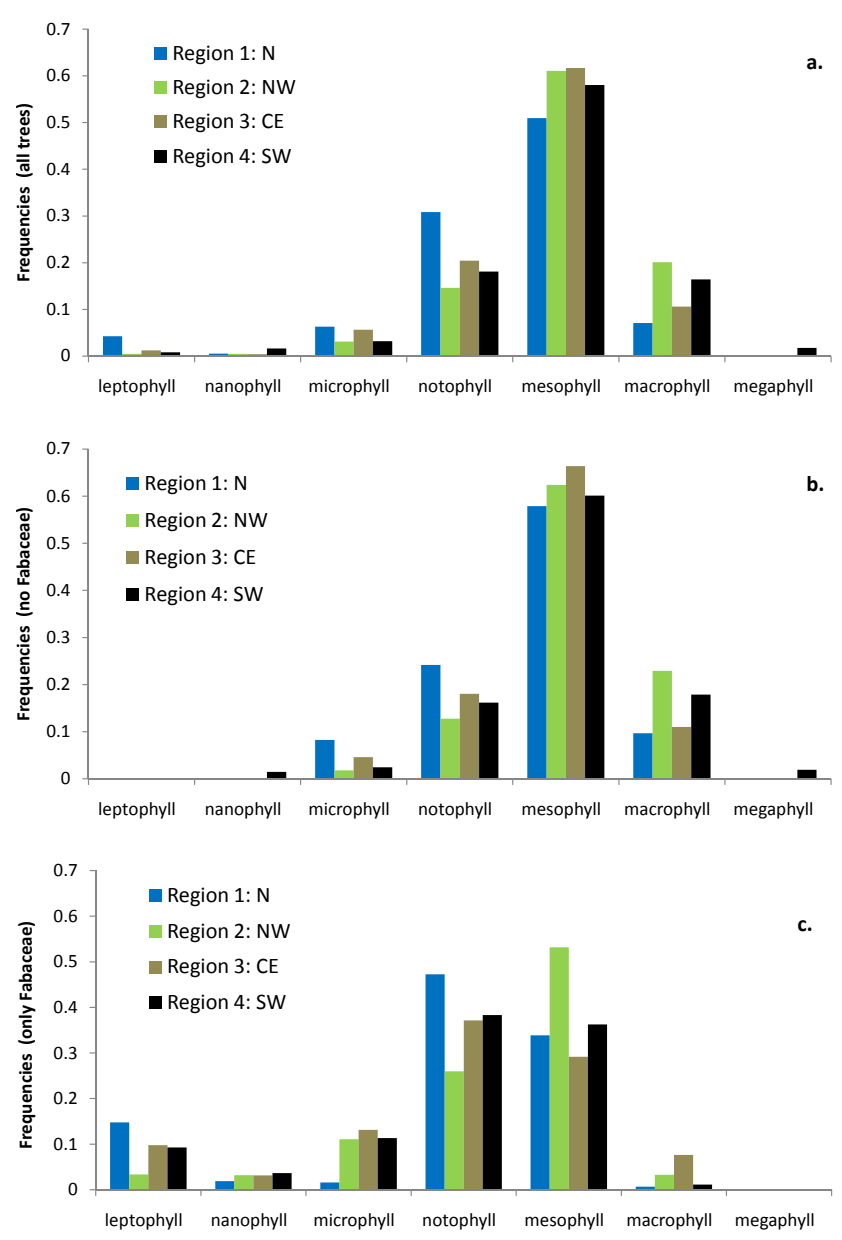

Fig. 5. The mean frequency ( 0 to 1 ) of different leaf size categories across the four Amazonian regions (Region 1, north; Region 2, northwest; Region 3, central and east; Region 4, Southwest Amazonia). Figure (a) represents all individual trees; figure (b) illustrates all individual trees with the exception of members of the Fabaceae; figure (c) shows only trees from the Fabaceae taxa.

\subsection{Environmental correlates of leaf size}

The proportion of species per site with large leaves was significantly correlated with three precipitation metrics used in the study: length of the dry season (months $<100 \mathrm{~mm}$ rainfall), maximum water deficit, and a metric of the variation in water availability based on the standard deviation of total rainfall (full results given in Table 3). However, no significant relationships were seen at the individual level or for species or individuals when the leaf size metric was the proportion of trees per plot with "very-large" leaves (Categories 6 and 7).

Analyses of the large leaf subsets of data controlling for the influence of the Fabaceae - with Fabaceae trees removed

tion $(0.1 \%)$ of the total number of species. 

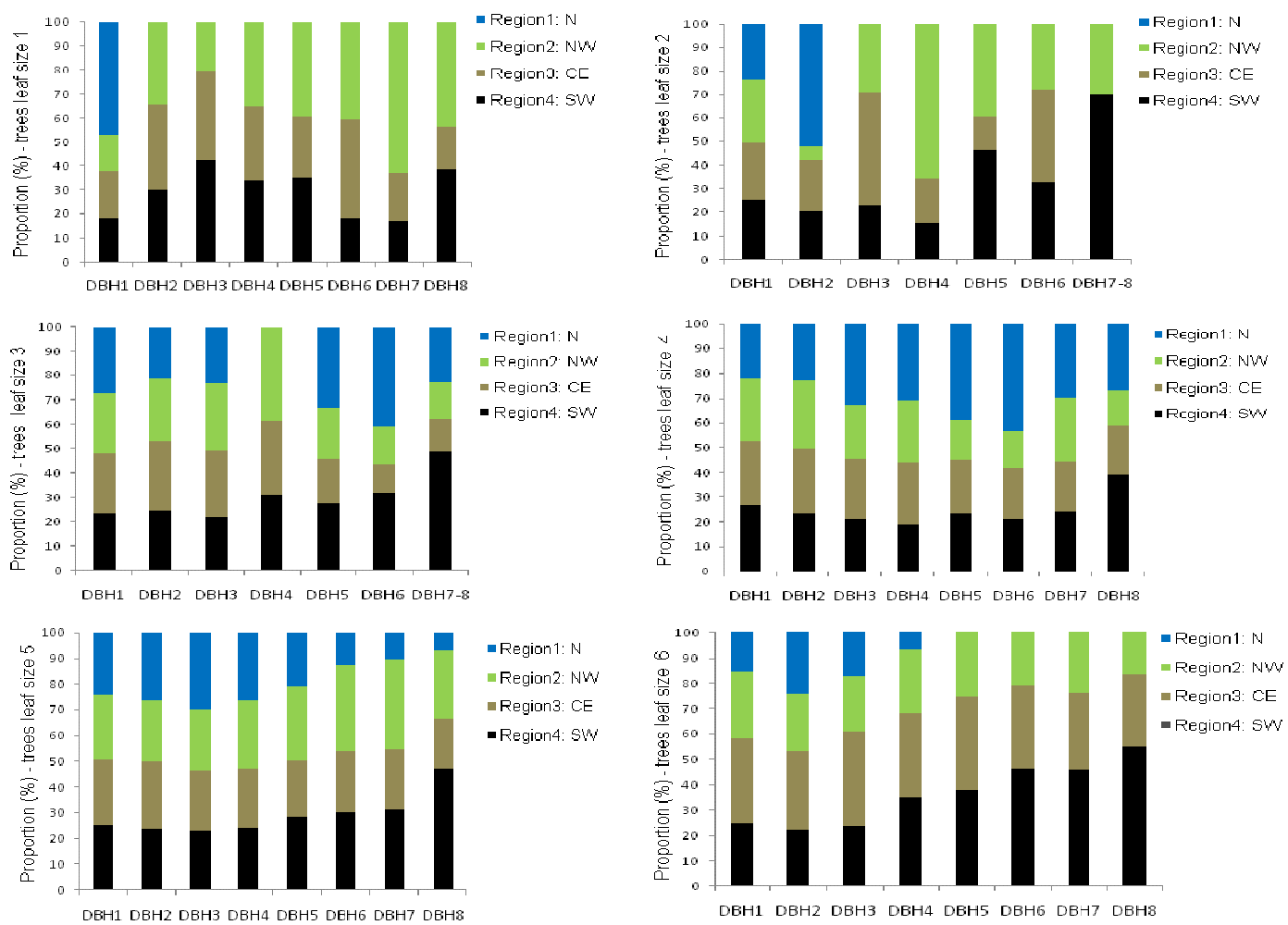

Fig. 6. Relative abundance (percentage) of trees in each diameter (DBH) class for each individual leaf size category. The relative abundance is calculated following two steps: firstly, relative abundance within the region; secondly, relative abundance among regions to allow comparison. DBH1 $=100-190 \mathrm{~mm}$; DBH2 => 190-280 mm; DBH3=>280-370 mm; DBH4=>370-460 mm; DBH5=>460-550 mm; DBH6=>550$640 \mathrm{~mm}$; DBH7=>640-730 mm; DBH8=>730 mm. The regions are: Region 1, North Amazonia; Region 2, Northwest Amazonia; Region 3, Central and East Amazonia; Region 4, Southwest Amazonia.

and with only Fabaceae trees included - also resulted in a small number of significant correlations (Table 3). When the Fabaceae were removed, the proportion of trees with large leaves and "very-large" leaves did not correlate with any variables. However, when the Fabaceae were analysed separately significant correlations were found between the proportion of trees with large leaves and length of the dry season. The proportion of Fabaceae individuals with "verylarge" leaves only correlated with the coefficient of variation (SD) of rainfall (Table 3).

The relationship between soil fertility and leaf size was complex and revealed no strong patterns or consistent associations. From the global dataset (individual and clustered leaf categories of proportion of individual trees and species) only one correlation was significant - between the proportion of individual trees with in the smallest leaf size category and soil fertility (Table 4). No correlations were found when we removed the Fabaceae, while only Categories 6 and "verylarge" leaves were correlated within the Fabaceae trees subset (Table 4). We also explored total phosphorus availability (as an additional measure of soil fertility) and, once again, no correlations were found.

Analyses within Region 2 did not reveal any significant correlation with soil fertility and leaf size, while analyses within Region 3 (Central-East Amazonia) produced only one significant (positive) correlation between individual trees and leaf size Category 1. An interesting contrast is found in Region 4 (Southwest Amazonia) with 18 significant results supporting an inverse correlation between the proportions of individual trees with large leaves and soil fertility (Table 4) - the opposite trend to that observed by previous authors (Wright et al., 2007).

\section{Discussion}

Richards (1952), in his pioneering study on tropical rainforests, noted that plants of different families in a tropical forest tended towards similar morphologies far more than species, even of the same genera, in temperate forests. This is very apparent for traits such as leaf size, where species within tropical forests can be remarkably homogenous in the leaf size properties that they possess. In lowland rainforests the predominant leaf size category is mesophyll (sensu Raunkiaer, 1934) - Grubb and his colleagues describe $64 \%$ of species in Ecuador, $84 \%$ of their sample in Brazil, and $98 \%$ of their sample in Australia as belonging to the mesophyll category (Grubb et al., 1963). Turner (2001) 

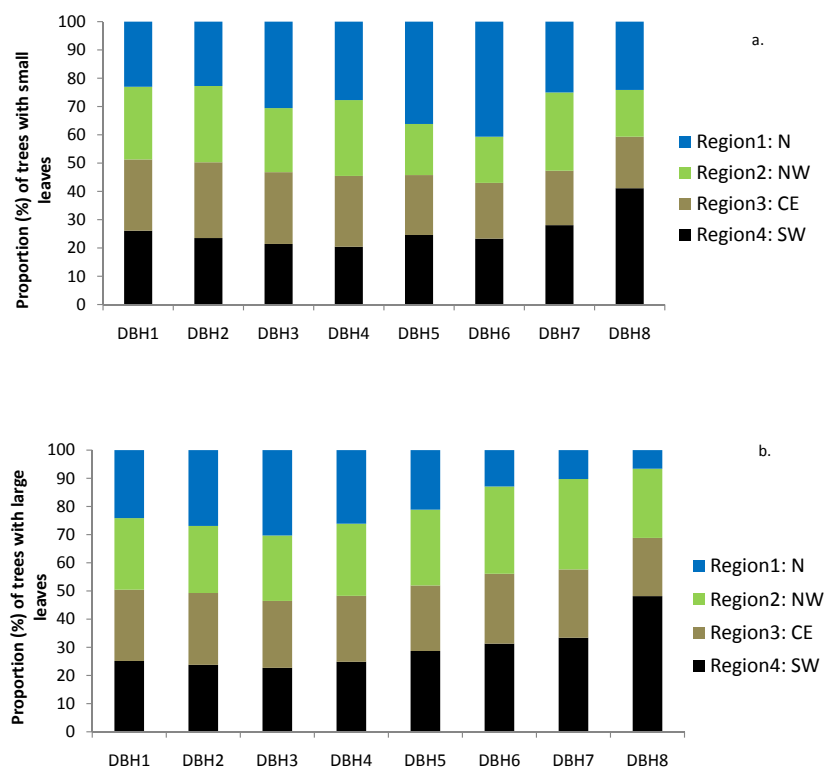

Fig. 7. Relative abundance of trees in each diameter (DBH) class for clustered (small and large) leaf size category. The relative abundance is calculated following two steps: firstly, relative abundance within the region; secondly, relative abundance among regions to allow comparison. DBH1 $=100-190 \mathrm{~mm}$ DBH2 $=>190-280 \mathrm{~mm}$; $\mathrm{DBH} 3=>280-370 \mathrm{~mm} ; \quad \mathrm{DBH} 4=>370-460 \mathrm{~mm} ; \quad \mathrm{DBH} 5=>460$ $550 \mathrm{~mm} ; \quad$ DBH6 $=>550-640 \mathrm{~mm} ; \quad \mathrm{DBH} 7=>640-730 \mathrm{~mm}$; $\mathrm{DBH} 8=>730 \mathrm{~mm}$. The regions are: Region 1, North Amazonia; Region 2, Northwest Amazonia; Region 3, Central and East Amazonia; Region 4, Southwest Amazonia. (a) Trees with small leaves (size Categories 1 to 4). (b) Trees with large leaves (size Categories 5 and 6).

proposes that trees in this category normally constitute approximately three-quarters of all species in lowland tropical rainforests across the globe. The current pan-Amazon study supports these findings, with $73.6 \%$ of species identified belonging to this size category. This result also supports the observation that the mesophyll category dominates in Neotropical rainforests (Grubb et al., 1963; Thompson et al., 1992; Kelly et al., 1994). Another characteristic feature of tropical rainforests is to have a small proportion of (non-palm) species with very large leaves. Once again this was further supported by this study in that we observed $0.01 \%$ of species with leaves in the megaphyll size category.

\subsection{Spatial trends and environmental correlates in leaf size}

Our study demonstrates complex patterns of variation in leaf size characteristics across the Amazon rainforest. At the crudest level of analysis there is a trend towards greater proportions of individuals and species in large leaf size categories in the western plots. The relatively lower proportion of trees with large leaves in the Guiana Shield may be due to the unusual ecology of the area (see ter Steege et al., 2006) re- sulting in a high proportion of Fabaceae, many of which are characterized by the possession of small leaves (or leaflets).

These spatial trends in leaf size can be interpreted in relation to previous macrogeographic studies in the Amazon. Most significantly, ter Steege et al. (2006) recently used inventory data to identify two major gradients in tree composition and function across Amazonia. The first gradient stretches from the Guiana Shield to Southwestern Amazonia and is primarily characterized by changes in the abundance of several common species of legumes in the Guyanas. This observed gradient in tree composition is paralleled by declines in functional traits such as wood density and seed mass. The main ecological driver of this gradient is hypothesized to be the increasingly poor soils as one approaches the northeastern corner of Amazonia. The second gradient stretches from Colombia to Southeastern Amazonia and is characterized by the increasing presence of more drought-adapted species in the forests on the southeastern edge of Amazonia, which is postulated to be driven by a parallel gradient of dry season length (ter Steege et al., 2006).

In the present study the relative predominance of largerleaved species in West and Southwest Amazonia closely aligns with the scores for the second axis of ter Steege's DCA analysis of genus level community composition (ter Steege et al., 2006) and indicates a possible influence of length of the dry season on leaf size. This interpretation is further supported, although weakly, by the spatially-corrected OLS regressions, which identified three metrics of water availability (see Materials and Methods) as being significantly associated with the proportion of tree species with large leaves. However, the data do not generate a clear signal when the Fabaceae are excluded from the dataset, or when the Fabaceae are analysed independently. It is worth noting that ter Steege et al. (2006) did not correct for spatial autocorrelation, and it is not clear if the pattern would be the same if it had been accounted for.

In summary, the data presented here do not provide any clear support for the hypothesis that leaf size in rainforests is positively correlated with annual rainfall. This may be due to the geographic scale of the study. However, the results do broadly support the work of Dolph and Dilcher (1980), who reported distinct leaf size proportions in different tropical forest life zones (dry forests, wet forests, montane forests) rather than a positive environment gradient that correlates leaf size and climate, reflecting an increase in temperature and/or precipitation and increase in the proportion of leaf size (Dolph and Dilcher, 1980).

The relationship between soil fertility and leaf size proved to be complex and revealed no strong patterns. This is in agreement with McDonald et al. (2003) who suggest that there is no clear basis for the negative correlation between leaf size and lower soil phosphorus levels. Nevertheless, they did find a pattern of decreasing leaf size (length, width, leaf surface area) in oligotrophic soils (while controlling for rainfall) in Southeast Australia. There study spanned a whole 
Table 3. OLS regression analysis of large leaves of species and individual trees (and variation of sub-datasets: only Fabaceae trees, Fabaceae trees removed) in relation to climatic variables controlled for spatial autocorrelation. Spatial structure was accounted for in all regressions by adding eigenvector filters produced with the PCNM. Filters were omitted and only plots with measurements for all variables were used in the regressions. $\mathrm{SD}=$ standard deviation of annual rainfall (see Material and Methods) MWD=maximum water deficit.

\begin{tabular}{|c|c|c|c|c|c|c|}
\hline \multirow[b]{3}{*}{ Rainfall } & \multicolumn{3}{|c|}{ Species with large leaves } & \multicolumn{3}{|c|}{ Species with "very-large" leaves } \\
\hline & Std. Coeff./Coeff & $t$ & $p$ & Std. Coeff./Coeff & $t$ & $p$ \\
\hline & $0.273(<0.001)$ & 1.249 & 0.214 & $0.152(<0.001)$ & 0.598 & 0.551 \\
\hline SD & $-0.441(-0.004)$ & -2.541 & $0.012 *$ & $0.067(<0.001)$ & 0.319 & 0.75 \\
\hline Length dry & $1.385(0.089)$ & 4.511 & $<0.001 *$ & $0.354(0.024)$ & 1.022 & 0.309 \\
\hline \multirow[t]{3}{*}{ MWD } & $0.808(<0.001)$ & 4.354 & $<0.001 *$ & $0.052(<0.001)$ & 0.249 & 0.804 \\
\hline & \multicolumn{3}{|c|}{ Individuals with large leaves } & \multicolumn{3}{|c|}{ Individuals with "very-large" leaves } \\
\hline & Std. Coeff./Coeff. & $t$ & $p$ & Std. Coeff./Coeff & $t$ & $p$ \\
\hline Rainfall & $0.266(<0.001)$ & 1.355 & 0.178 & $-0.106(<0.001)$ & -0.433 & 0.666 \\
\hline SD & $0.089(-0.003)$ & -0.594 & 0.554 & $-0.086(-0.001)$ & -0.458 & 0.648 \\
\hline Length dry & $0.336(0.07)$ & 1.289 & 0.2 & $-0.049(-0.006)$ & -0.151 & 0.881 \\
\hline \multirow[t]{3}{*}{ MWD } & $-0.051(<0.001)$ & -0.311 & 0.756 & $0.071(<0.001)$ & 0.303 & 0.762 \\
\hline & \multicolumn{3}{|c|}{ Individuals (not Fabaceae) with large leaves } & \multicolumn{3}{|c|}{ Individuals (not Fabaceae) with "very-large" leaves } \\
\hline & Std. Coeff./Coeff. & $t$ & $p$ & Std. Coeff./Coeff. & $t$ & $p$ \\
\hline Rainfall & $0.412(<0.001)$ & 1.296 & 0.198 & $0.168(<0.001)$ & 0.547 & 0.585 \\
\hline SD & $-0.26(-0.003)$ & -1.061 & 0.291 & $-0.199(-0.003)$ & -0.801 & 0.425 \\
\hline Length dry & $0.65(0.052)$ & 1.524 & 0.13 & $0.304(0.031)$ & 0.7 & 0.486 \\
\hline \multirow[t]{3}{*}{ MWD } & $0.066(<0.001)$ & 0.334 & 0.739 & $0.057(<0.001)$ & 0.215 & 0.83 \\
\hline & \multicolumn{3}{|c|}{ Individuals (only Fabaceae) with large leaves } & \multicolumn{3}{|c|}{ Individuals (only Fabaceae) with "very-large" leaves } \\
\hline & Std. Coeff./Coeff. & $t$ & $p$ & Std. Coeff./ Coeff. & $t$ & $p$ \\
\hline Rainfall & $0.488(<0.001)$ & 1.487 & 0.14 & $0.059(<0.001)$ & 0.261 & 0.795 \\
\hline SD & $-0.518(-0.0012)$ & -1.966 & 0.052 & $-0.453(-0.003)$ & -2.505 & $0.014^{*}$ \\
\hline Length dry & $1.065(0.196)$ & 2.364 & $0.02 *$ & $0.492(0.015)$ & 1.539 & 0.127 \\
\hline MWD & $0.068(<0.001)$ & 0.319 & 0.751 & $0.148(<0.001)$ & 0.779 & 0.438 \\
\hline
\end{tabular}

order of magnitude of total soil $P$ (range $22-2063 \mu \mathrm{g} \mathrm{g}^{-1}$ ) and used continuous measurements of leaf dimensions rather than size categories (McDonald et al., 2003). This illustrates one of the limitations of the present study and methodology, and demonstrates the critical need in macrogeographic studies for establishing the appropriate scale of analysis in order to uncover genuine ecological patterns.

\subsection{Leaf size and tree characteristics}

The postulated functional association between water availability and leaf size may also underlie the observed negative relationship between leaf size and wood density. Wright et al. (2007) argue that trees with lower wood density have larger-diameter stem vessels and can therefore transport more water and have a greater total leaf area per stem. As interspecific variation in leaf area per stem is driven more by leaf size than number of leaves (e.g. Ackerly, 2004), all other things being equal, species with low density wood tend to have larger leaves. Wood density might therefore contribute to the observed relationship between the water availability metrics and leaf size if the enhanced water transport abilities of large-leaved, low wood density species is a disadvantage in sites with lower water availability.

It should be noted, however, that wood density itself has a complex relationship with precipitation. Thus, while Wiemann and Williamson (2002) found a positive correlation between wood density and mean annual precipitation in their comparison of North American and South American tree communities, ter Steege and Hammond (2001) found that the variation in mean wood density within the Guyanas was not correlated with precipitation. On the other hand, BarajasMorales (1987) found that mean wood density was negatively related to precipitation in two tropical forests in Mexico. Wood density has also been observed to vary between Amazonian regions and with altitude. A recent study in the Amazon described a complex spatial pattern of significant decreases in wood density with increasing altitude and significant differences among low-altitude Amazonian regions: the forests of Western Amazonia have significantly lower mean wood density than those of Eastern and Central Amazonia (Chave et al., 2006). In conclusion, wood density should be considered as one potentially important factor driving spatial trends in leaf size in Amazonia but further manipulative and 
Table 4. Correlation analyses of leaf size categories and soil fertility (sum of bases). Blank cells represent no correlation. "“" and "+"” indicate the direction of the correlation. A capitalized letter represents a significant spatially corrected correlation (details below table). S, L, $\mathrm{VL}=$ merged categories: small leaves, large leaves, and "very-large" leaves.

\begin{tabular}{|c|c|c|c|c|c|c|c|c|c|c|c|}
\hline \multicolumn{2}{|c|}{ LEAF size categories } & 1 & 2 & 3 & 4 & 5 & 6 & 7 & $\mathrm{~S}$ & $\mathrm{~L}$ & VL \\
\hline Global & $\begin{array}{l}\text { Proportion of individual trees within a plot } \\
\text { Proportion of species within a plot } \\
\text { Proportion of individual trees (Fabaceae removed) } \\
\text { Proportion of individual trees (Fabaceae only) }\end{array}$ & $+^{\mathrm{A}}$ & & & & & $+^{\mathrm{B}}$ & & & & ${ }_{+} \mathrm{C}$ \\
\hline $\begin{array}{l}\text { Northwest } \\
\text { Amazonia }\end{array}$ & $\begin{array}{l}\text { Proportion of individual trees within a plot } \\
\text { Proportion of species within a plot } \\
\text { Proportion of individual trees (Fabaceae removed) } \\
\text { Proportion of individual trees (Fabaceae only) }\end{array}$ & & & $\begin{array}{l}- \\
- \\
-\end{array}$ & $\begin{array}{l}- \\
- \\
-\end{array}$ & + & $\begin{array}{l}+ \\
+\end{array}$ & & $\begin{array}{l}- \\
- \\
-\end{array}$ & $\begin{array}{l}+ \\
+ \\
+\end{array}$ & $\begin{array}{l}+ \\
+\end{array}$ \\
\hline $\begin{array}{l}\text { Central } \\
\text { and East } \\
\text { Amazonia }\end{array}$ & $\begin{array}{l}\text { Proportion of individual trees within a plot } \\
\text { Proportion of species within a plot } \\
\text { Proportion of individual trees (Fabaceae removed) } \\
\text { Proportion of individual trees (Fabaceae only) }\end{array}$ & $+^{\mathrm{D}}$ & & & & & & & & & \\
\hline $\begin{array}{l}\text { Southwest } \\
\text { Amazonia }\end{array}$ & $\begin{array}{l}\text { Proportion of individual trees within a plot } \\
\text { Proportion of species within a plot } \\
\text { Proportion of individual trees (Fabaceae removed) } \\
\text { Proportion of individual trees (Fabaceae only) }\end{array}$ & & & & $\begin{array}{l}+{ }_{+\mathrm{E}}^{\mathrm{E}} \\
+{ }_{+}^{\mathrm{I}}\end{array}$ & & $\begin{array}{l}-\mathrm{F} \\
-\mathrm{J} \\
-\mathrm{O}\end{array}$ & & $\begin{array}{l}{ }_{+}^{\mathrm{G}} \\
{ }_{+}^{\mathrm{K}} \\
{ }_{+}^{\mathrm{P}}\end{array}$ & $\begin{array}{l}-{ }^{\mathrm{H}} \\
-\mathrm{L}\end{array}$ & ${ }_{-}^{-}$ \\
\hline
\end{tabular}

Correlation results $\left(n\right.$, Pearson's $\left.F_{\text {corrected }}, d f_{\text {corrected }}, p_{\text {corrected }}\right)$. A) $n=51$, Pearson's $F_{\text {corrected }}=4.953$, DF corrected $=43.9, p_{\text {corrected }}=0.031$; $\mathrm{B}$ and C) $51,0.468,14.018,28,0.008$; D) 15, 0.599, 7.137, 12.765, 0.019; E) 16, 0.579, 5.818, 11, 0.034; F) 16, -0.503, 5.094, 16, 0.031; G) $16,0.585,6.944,13,0.02$; H) $16,-0.585,6.944,13,0.02$; I) $16,0.307,9.153,87,0.003$; J) 16, $-0.493,5.391,16,0.03$; K) $16,0.379$, $7.081,42,0.011$; L) $16,-0.379,7.081,42,0.011$; M) $16,-0.516,4.989,13.7,0.043$; N) 16, 0.482, 7.62, 25.22, 0.011; O) 16, -0.544, $4.991,11.878,0.045$; P) 16, 0.471, 5.66, 19.85, 0.027 .

comparative work is clearly desirable in order to better understand the complex trade-offs and selective pressures on these two traits.

\section{Conclusions}

This study set out to address three key hypotheses. First, that small leaves are an adaptation to relatively dry conditions and will show a macrogeographic pattern that reflects this. The regional distribution of leaf size categories is broadly consistent with this hypothesis, although the spatially corrected regressions failed to provide strong evidence for quantitative relationships between leaf size and precipitation metrics. Second, that small leaves are favoured on oligotrophic soils. No evidence was found in support of this hypothesis, possibly because of the numerous trade-offs with other ecological and physiological factors, or the limitations of the data used in the analysis. Finally, that there is a negative relationship between leaf size and wood density. Like many other studies we found strong support in favour of this hypothesis, suggesting that this relationship is one of the fundamental constraints on leaf size evolution.

Although the regional trends in leaf size described here fit well with our current understanding of the macroecology of the Amazon, other factors not easily picked up at this resolution of analysis may also be influencing observed patterns. Regional trends in leaf size might also be influenced by allometry, development and phylogeny in constraining the expression of this trait in different ways in different habitats (Cornelissen, 1999). It is even possible that other factors, such as herbivory, may also influence the geographic distribution of leaf size since small leaves are often thicker and more resistant to herbivores. Moles and Westoby (2000) have argued that species with smaller leaves may suffer less herbivory during leaf expansion because the leaf expands for a shorter period. In addition, it is necessary to keep in mind the possibility that site level effects to minimize water stress (i.e. hydraulic lift and deep soils and roots) might confound the effects of climate on leaf structure. Finally, it should also be noted that while single plot-based attributes such as proportion of trees in a given leaf size category may produce useful correlates with biophysical variables at large spatial scales, these may break down under varying spatial, temporal and environmental scales (Gillison and Carpenter, 1997), thus limiting their utility. However, despite potential difficulties in inferring causal relationships, macrogeographic studies of functional traits such as leaf size clearly provide important tools to help describe the still poorly-understood functional ecology of Amazonia (ter Steege et al., 2006). 
Acknowledgements. We thank I. Kühn for advice about spatial analyses; M. Ladle for comments and copy-editing; and the whole RAINFOR network. C. Vriesendorp, F. Borchsenius, B. M. Thiers, and L. Willemse have provided herbaria data. A. Malhado's PhD was funded by Oxford University's Clarendon scholarship and Overseas Research Scheme award. We thank J. Lloyd and one anonymous referee for useful and challenging comments.

Edited by: J. Lloyd

\section{References}

Ackerly, D. D.: Canopy structure and dynamics: integration of growth processes in tropical pioneer trees, in: Tropical Forest Plant Ecophysiology, Chapman \& Hall, NY, US, 619-658, 1996.

Ackerly, D. D. and Donoghue, M. J.: Leaf size, sapling allometry, and Corner's rules: phylogeny and correlated evolution in maples (Acer), Am. Nat., 152, 767-791, 1998.

Ackerly, D. D. and Reich, P. B.: Convergence and correlations among leaf size and function in seed plants: a comparative test using independent contrasts, Am. J. Bot. 9, 1272-1281, 1999.

Ackerly, D. D.: Functional strategies of chaparral shrubs in relation to seasonal water deficit and disturbance, Ecol. Monogr., 74, 2544, 2004.

Aragão, L. E. O. C., Malhi, Y., Roman-Cuesta, R. M., Saatchi, S., Anderson, L. O., and Shimabukuro, Y. E.: Spatial patterns and fire response of recent Amazonian droughts, Geophys. Res. Lett., 34, L07701, doi:10.1029/2006GL028946, 2007.

Baker, T. R., Phillips, O. L., Malhi, Y., Almeida, S., Arroyo, L., Di Fiore, A., Erwin, T., Killeen, T., Laurance, S. G., Laurance, W. F., Lewis, S. L., Lloyd, J., Monteagudo, A., Neill, D. A., Patiño, S., Pitman, N. C., Silva, J. N. M., and Vásquez-Martínez, R.: Variation in wood density determines spatial patterns in Amazonian forest biomass, Glob. Change Biol., 10, 1-18, 2004.

Baker, T. R. and Lopez-Gonzalez, G.: Wood density, in: RAINFOR: Functional Traits Database: Date of extraction: August 2006.

Barajas-Morales, J.: Wood specific gravity in species from two tropical forests in Mexico, IAWA Journal, 8, 143-148, 1987.

Cain, S. A., Oliveira Castro, G. M., Pires, J. M., and da Silva, N. T.: Application of some phytosociological techniques to Brazilian rain forest, Am. J. Bot., 43, 911-941, 1956.

Chave, J., Muller-Landau, H. C., Baker, T. R., Easdale, T. A., ter Steege, H., and Webb, C. O.: Regional and phylogenetic variation in wood density among 2456 Neotropical tree species, Ecol. Appl., 16, 2356-2367, 2006.

Cornelissen, J. H. C.: A triangular relationship between leaf size and seed size among woody species: allometry, ontogeny, ecology and taxonomy, Oecologia, 118, 248-255, 1999.

Dawkins, R.: The Extended Phenotype, Oxford University Press, Oxford, 1982

Dolph, G. E. and Dilcher, D. L.: Variation in leaf size with respect to climate in the tropics of the Western Hemisphere, B. Torrey Bot. Club., 107, 154-162, 1980.

Dutilleul, P.: Modifying the t-test for assessing the correlation between 2 spatial processes, Biometrics, 49, 305-314, 1993.

Falster, D. S. and Westoby, M.: Leaf size and angle vary widely across species: what consequences for light interception?, New. Phytol., 158, 509-525, 2003.
Gillison, A. N. and Carpenter, G.: A generic plant functional attribute set and grammar for dynamic vegetation description and analysis, Funct. Ecol., 11, 775-783, 1997.

Givnish, T. J.: On the adaptive significance of compound leaves, with particular reference to tropical trees, in: Tropical Trees as Living Systems, Cambridge University Press, New York, US, 351-380, 1978.

Givnish, T. J.: On the adaptive significance of leaf form, in: Topics in Plant Population Biology, Columbia University Press, New York, USA, 375-407, 1979.

Givnish, T. J.: Leaf and canopy adaptations in tropical forests, in: Physiological Ecology of Plants in the Wet Tropics, Junk, The Hague, Netherlands, 51-58, 1984.

Givnish, T. J.: Comparative studies of leaf form - assessing the relative roles of selective pressures and phylogenetic constraints, New Phytol., 106, 131-160, 1987.

Givnish, T. J. and Vermeij, G. J.: Sizes and shapes of liana leaves, Am. Nat. 110, 743-778, 1976.

Grubb, P. J., Lloyd, J. R., Pennington, T. D., and Whitmore, T. C.: A comparison of montane and lowland rain forest in Ecuador I. The forest structure, physiognomy, and floristics, J. Ecol., 51, 567-601, 1963.

Huffman, G. J. and Bolvin, D. T.: TRMM and Other Data Precipitation Data Set Documentation. Laboratory for Atmospheres, NASA Goddard Space Flight Center and Science Systems and Applications, Inc. 2007.

Kelly, D. L., Tanner, E. V. J., Nic Lughadha, E. M., and Kapos, V.: Floristics and biogeography of a rain forest in the Venezuelan Andes, J. Biogeogr., 21, 421-440, 1994.

Legendre, P.: Spatial autocorrelation: trouble or new paradigm?, Ecology, 74, 1659-1673, 1993.

Lloyd, J. and Farquhar, G. D.: Effects of rising temperatures and $\left[\mathrm{CO}_{2}\right]$ on the physiology of tropical forest trees, Philos. T. Roy. Soc. B, 363, 1811-1817, 2008.

Malhado, A. C. M., Whittaker, R. J., Malhi, Y., Ladle, R. J., ter Steege, H., Butt, N., Aragão, L. E. O. C., Quesada, C. A., Murakami-Araujo, A., Phillips, O. L., Peacock, J., LópezGonzález, G., Baker, T. R., Anderson, L. O., Arroyo, L., Almeida, S., Higuchi, N., Killeen, T. J., Monteagudo, A., Neill, D. A., Pitman, N. C. A., Prieto, A., Salomão, R. P., Vásquez-M., R., Laurance, W. F., and Ramírez A., H.: Spatial distribution and functional significance of leaf lamina shape in Amazonian forest trees, Biogeosciences, 6, 1577-1590, 2009, http://www.biogeosciences.net/6/1577/2009/

Malhi, Y., Baker, T. R., Phillips, O. L., Almeida, S, Alvarez, E., Arroyo, L., Chave, J., Czimczik, C. I., Di Fiore, A., Higuchi, N., Killeen, T. J., Laurance, S. G., Laurance, W. F., Lewis, S. L., Mercado, L. M., Monteagudo, A., Neill, D. A., Núñez Vargas, P., Patiño, S., Pitman, N. C. A., Quesada, C. A., Silva, N., Torres Lezama, A., Vásquez-Martínez, R., Terborgh, J., Vinceti, B., and Lloyd, J.: The above-ground coarse woody productivity of 104 Neotropical forest plots, Glob. Change Biol., 10, 563-591, 2004.

McDonald, P. G. M., Fonseca, C. R., Overtons, J., and Westoby, M.: Leaf-size divergence along rainfall and soil-nutrient gradients: is the method of size reduction common among clades?, Funct. Ecol., 17, 50-57, 2003.

Midgley, J. J. and Bond, W. J.: Leaf size and inflorescence size may be allometrically related traits, Oecologia, 78, 427-429, 1989.

Moles, A. T. and Westoby, M.: Do small leaves expand faster than 
large leaves, and do shorter expansion times reduce herbivore damage?, Oikos, 90, 517-524, 2000.

Parkhurst, F. and Loucks, L.: Optimal leaf size in relation to environment, J. Ecol., 60, 505-537, 1972.

Peacock, J., Baker, T. R., Lewis, S. L., Lopez-Gonzalez, G., and Phillips, O. L.: The RAINFOR database: monitoring forest biomass and dynamics, J. Veg. Sci., 18, 535-542, 2007.

Phillips, O. L., Aragão, L. E., Lewis, S. L., Fisher, J. B., Lloyd, J. L., López-González, G., Malhi, Y., Monteagudo, A., Peacock, J., Quesada, C. S., van der Heijden, G. M., Almeida, S., Amaral, I., Arroyo, L., Aymard, G., Baker, T. R., Bánki, O., Blanc, L., Bonal, D., Brando, P., Chave, J., Alves de Oliveira, A. C., Dávila Cardozo, N., Czimczik, C. I., Feldpausch, T. R., Freitas, M. A., Gloor, E. U., Higuchi, N., Jiménez, E., Lloyd, G., Meir, P., Mendoza, C., Morel, A., Neill, D. A., Nepstad, D, Patiño, A., Peñuela, M. C., Prieto, A., Ramírez, F., Schwarz, M., Silva, J. E., Silveira, M., Sota Thomas, A., ter Steege, H., Stropp, J., Vásquez, R., Zelazowski, P., Alvarez Dávila, E., Andelman S., Andrade, A., Chao, K. J., Erwin, T., Di Fiore, A., Honorio, E., Keeling H. C., Killeen, T. J., Laurance, W. F., Peña Cruz, A., Pitman, N. C. A., Núñez Vargas, P., Ramírez-Angulo, H., Rudas, A., Salamão, R., Silva, N., Terborgh, J., and Torres-Lezama, A.: Drought sensitivity of the Amazon rainforest, Science, 323, 1344-1347, 2009.

Phillips, O., Baker T. R., Arroyo, L., Higuchi, N., Killeen, T., Laurance, W. F., Lewis, S. L., Lloyd, J., Malhi, Y., Monteagudo, A., Neill, D., Núñez Vargas, P., Silva, N., Terborgh, J., VásquezMartínez, R., Alexiades, M., Almeida, S., Brown, S., Chave, J., Comiskey, J. A., Czimczik, C. I., Di Fiore, A., Erwin, T., Kuebler, C., Laurance, S. G., Nascimento, H. E. M., Palacios, W., Patiño, S., Pitman, N., Olivier, J., Quesada, C. A., Saldias, M., Torres Lezama, A., and Vinceti, B.: Pattern and process in Amazon tree turnover, 1976-2001, Philos. T. Roy. Soc. B, 363, 381407, 2004.

Pleysier, J. L. and Juo, A. S. R.: A single-extraction method using silver-thiourea for measuring exchangeable cations and effective CEC in soils with variable charges, Soil Sci., 129, 205-211, 1980.

Quesada, C. A., Lloyd, J., Schwarz, M., Patĩo, S., Baker, T. R., Czimczik, C., Fyllas, N. M., Martinelli, L., Nardoto, G. B., Schmerler, J., Santos, A. J. B., Hodnett, M. G., Herrera, R., Luizo, F. J., Arneth, A., Lloyd, G., Dezzeo, N., Hilke, I., Kuhlmann, I., Raessler, M., Brand, W. A., Geilmann, H., Moraes Filho, J. O., Carvalho, F. P., Araujo Filho, R. N., Chaves, J. E., Cruz Junior, O. F., Pimentel, T. P., and Paiva, R.: Chemical and physical properties of Amazon forest soils in relation to their genesis, Biogeosciences Discuss., 6, 3923-3992, 2009,

http://www.biogeosciences-discuss.net/6/3923/2009/.
Rangel, T. F. L. V. B., Diniz-Filho, J. A. F., and Bini, L. M.: Towards an integrated computational tool for spatial analysis in macroecology and biogeography, Global Ecol. Biogeogr., 15, 321-327, 2006.

Raunkiaer, C.: The Life Forms of Plants and Statistical Plant Geography, Oxford University Press, Oxford, 632 pp., 1934.

Richards, P. W.: The Tropical Rain Forest: an Ecological Study, Cambridge University Press, Cambridge, 1952.

ter Steege, H. and Hammond, D. S.: Character convergence, diversity, and disturbance in tropical rain forest in Guyana, Ecology, 82, 3197-3212, 2001.

ter Steege, H., Pitman, N., Sabatier, D., Castellanos, H., Van der Hout, P., Daly, D. C., Silveira, M., Phillips, O., VásquezMartínez, R, Van Andel, T., Duivenvoorden, J., de Oliveira, A. A., Ek, R., Lilwah, R., Thomas, R., Van Essen, J., Baider, C., Maas, P., Mori, S., Terborgh, J., Vargas, P. N., Mogollón, H., and Morawetz, W.: A spatial model of tree alpha-diversity and tree density for the Amazon, Biodivers. Conserv., 12, 2255-2277, 2003.

ter Steege, H., Pitman, N. C. A., Phillips, O. L., Chave, J., Sabatier, D., Duque, A., Molino, J. F., Prévost, M. F., Spichiger, R., Castellanos, H., von Hildebrand, P., and Vásquez-Martínez, R.: Continental-scale patterns of canopy tree composition and function across Amazonia, Nature, 443, 444-447, 2006.

Thompson, J., Proctor, J., Viana, V., Milliken, W., Ratter, J. A., and Scott, D. A.: Ecological studies on a lowland evergreen rain forest on Maraca Island, Roraima, Brazil. I. Physical environment, forest structure and leaf chemistry, J. Ecol., 80, 689-703, 1992.

Turner, I. M.: The Ecology of Trees in the Tropical Rainforest, Cambridge University Press, Cambridge, 2001.

Vásquez-Martínez, R.: Flórula de las Reservas Biológicas de Iquitos, Perú, St Louis: Missouri Botanical Garden Press, 1997.

Webb, L. J.: A physiognomic classification of Australian rain forests, J. Ecol., 47, 551-570, 1959.

Westoby, M., Falster, D. S., Moles, A. T., Vesk, P. A., and Wright, I. J.: Plant ecological strategies: some leading dimensions of variation between species, Annu. Rev. Ecol. Syst., 33, 125-159, 2002.

Wiemann, M. C. and Williamson, G. B.: Geographic variation in wood specific gravity: effects of latitude, temperature, and precipitation, Wood Fiber Sci., 34, 96-107, 2002.

Wright, I. J., Ackerly, D. D., Bongers, F., Harms, K. E., IbarraManriquez, G., Martinez-Ramos, M., Mazer, S. J., MullerLandau, H. C., Paz, H., Pitman, N. C. A., Poorter, L., Silman, M. R., Vriesendorp, C. F., Webb, C. O., Westoby, M., and Wright, S. J.: Relationships among ecologically important dimensions of plant trait variation in seven Neotropical forests, Ann. Bot., 99, 1003-1015, 2007. 